\title{
Aplicación fotogramétrica para el análisis dinámico de barrancas. Caso barrancas Ojo Salado y Seca, en el Volcán Citlaltépetl, México
}

\author{
Rogelio Ramos-Aguilar ${ }^{1}$, rogelio.ramos@correo.buap.mx; Patricia Máximo-Romero ${ }^{1}$, \\ patricia.maximo@correo.buap.mx; Blanca Susana Soto-Cruz ${ }^{2}$; Salvador Alcántara- \\ Iniesta $^{2}$; María de la Cruz Vázquez-García ${ }^{3}$; Aimel Tlacuatl-Sánchez ${ }^{4}$; Alberto Reyes- \\ Galicia $^{4}$; Lucía González-Franco ${ }^{4}$
}

\begin{abstract}
RESUMEN
Se presenta un análisis fotogramétrico de las barrancas Ojo Salado y Seca en el Volcán Citlaltépetl, que se encuentran en el área de influencia de los poblados de Cuiyachapa y Tetelcingo, en el estado de Veracruz. Se calculó la aceleración local de la gravedad, presión atmosférica y pendiente para cada barranca, con el fin de modelar de forma estructural la morfología de la zona de estudio. A través de mediciones micrométricas con estereoscopía se pudo inferir que las barrancas analizadas presentan un movimiento fundamental, paralelo al buzamiento de la superficie denominada como falla con desplazamiento vertical. En este trabajo se pone de manifiesto la importancia de la aplicación de métodos fotogramétricos para determinar áreas vulnerables a la acción dinámica de barrancas en laderas volcánicas, que drenan junto a los poblados de Cuiyachapa y Tetelcingo, en las laderas del Volcán Citlaltépetl. La modelación de datos 2D y 3D, correlacionada con datos de modelos fotogeomorfológicos, permitió determinar las escalas del mapa y del terreno. Se plantea una aplicación fotogramétrica para analizar la morfología de las barrancas activas.
\end{abstract}

Palabras clave: dinámica de barrancas, fotogrametría, Volcán Citlaltépetl.

\section{Photogrammetric application in the canyons Ojo Salado and Seca of Citlaltépetl volcano, México}

\begin{abstract}
A photrogrammetric analysis of the Ojo Salado and Seca canyons of Citlaltepetl Volcano, in the area of influence of the towns of Cuiyachapa and Tetelcingo, in the State of Veracruz is presented. The local acceleration of gravity, atmospheric pressure and slope for each canyon was calculated, in order to model the structural geomorphology of the study area. By micrometer measurements using stereoscopic development it could be inferred that the analyzed canyons, present a fundamental movement parallel to dip (inclination) of the surface referred to as fault with vertical displacement. This paper highlights the importance of the application of photogrammetric methods in Earth Sciences to examine two canyons in the Citlaltépetl Volcano, passing next to the towns of Cuiyachapa and Tetelcingo, acceleration of gravity, pressure and $2 \mathrm{D}$ and $3 \mathrm{D}$ modeling, data correlating with photogeomorphological models to determine scales of map and the terrain, and the unevenness of them using footholds. The purpose of this work is to encourage the application of photogrammetry in the area of Earth Sciences, specifically geomorphological development.
\end{abstract}

Keywords: dynamics of canyons, photogrammetry, Volcano Citlaltepetl.

Recibido el 15 de septiembre de 2015, aceptado el 30 de noviembre de 2015.

Facultad de Ingeniería, Benemérita Universidad Autónoma de Puebla, Av. San Claudio y 18 Sur, C.U., Puebla, México.

2 Centro de Investigación en Dispositivos Semiconductores. Benemérita Universidad Autónoma de Puebla, México.

3 Bufete de Ingeniería en Telecomunicaciones y Sistemas.

4 Colegios de Ingeniería Topográfica y Geodésica. Benemérita Universidad Autónoma de Puebla, México. 


\section{INTRODUCCIÓN}

El Volcán Citlaltépetl o Pico de Orizaba es la montaña más alta de México, con 5.636 m.s.n.m. Cubre una extensión de $160.000 \mathrm{~m}^{2}$ entre Puebla y Veracruz; dos tercios de su extensión se ubican en territorio de Puebla. El Pico de Orizaba forma parte de la cordillera Sierra Madre Oriental.

Se identifican y analizan las características morfométricas de las barrancas más importantes del volcán, Ojo Salado y Seca, utilizando métodos fotogramétricos que permitieron establecer los valores de pendiente, gravedad local y presión atmosférica de cada barranca. Estudios previos se han realizado para determinar tensiones, deformaciones y resistencias al corte a través de modelos matemáticos que proporcionan una aproximación a la solución del problema, pero sin considerar métodos geodésicos en el cálculo de la pendiente y la gravedad, ya que éstos proporcionan resultados más aproximados a la realidad, tal como el efectuado por RAMOS et al. (2014). La aplicación de estos procedimientos son inéditos para el área de estudio de las barrancas Ojo Salado y Seca del Volcán Citlaltépetl, y constituyen un aporte para este tipo de investigaciones, sobre todo en los escenarios de activación dinámica de barranacas y derretimiento de cuerpos de nieve en hielo en las cimas de los edificios volcánicos. En la figura 1 se observa el mapa orográfico de la República Mexicana y la localización del Volcán Citlaltépetl. En las laderas del volcán se localizan poblados que podrían verse afectados por la acción dinámica de los barrancos en estudio (Fig. 2).

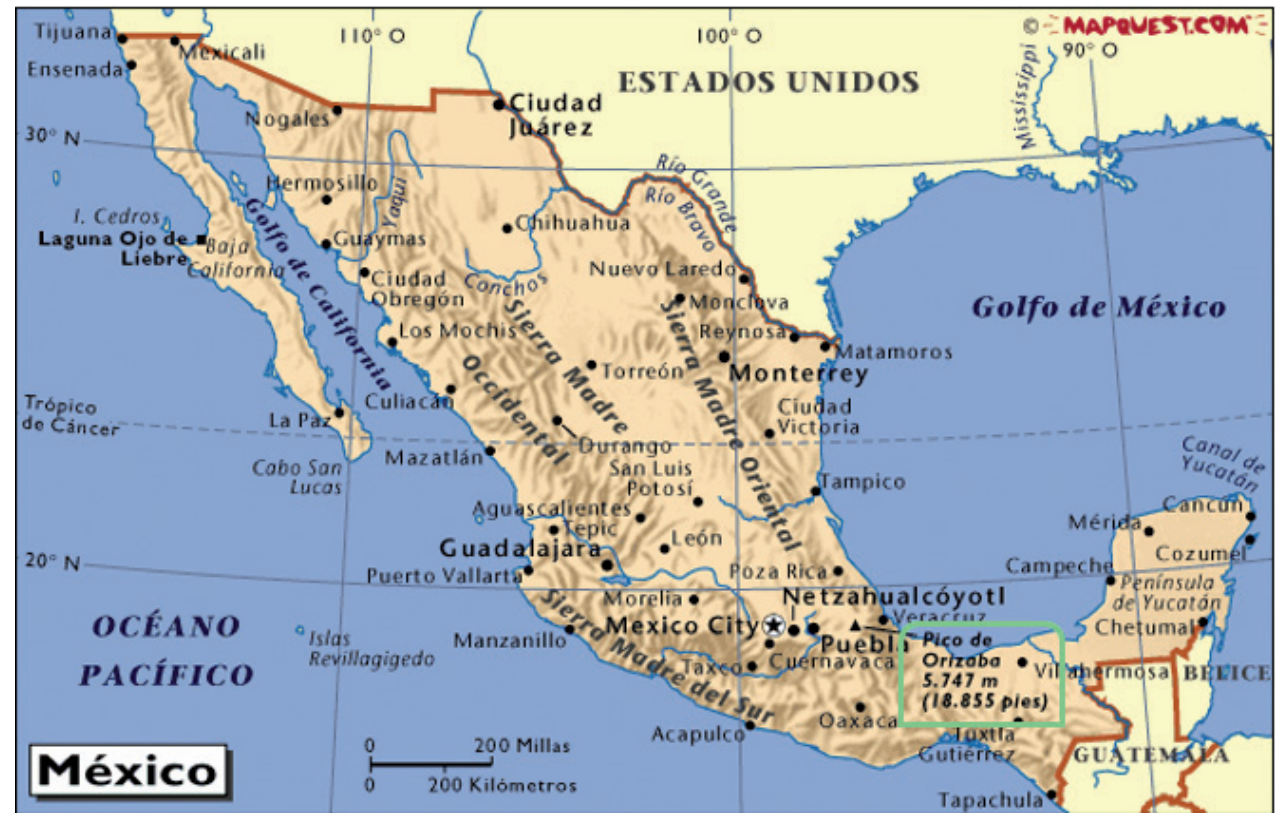

Fig. 1. Mapa orográfico de la República Mexicana con la localización del Volcán CitlaltépetL.

Fig. 1. Orographic map of México with the location of Citlaltépetl Volcano indicated. 


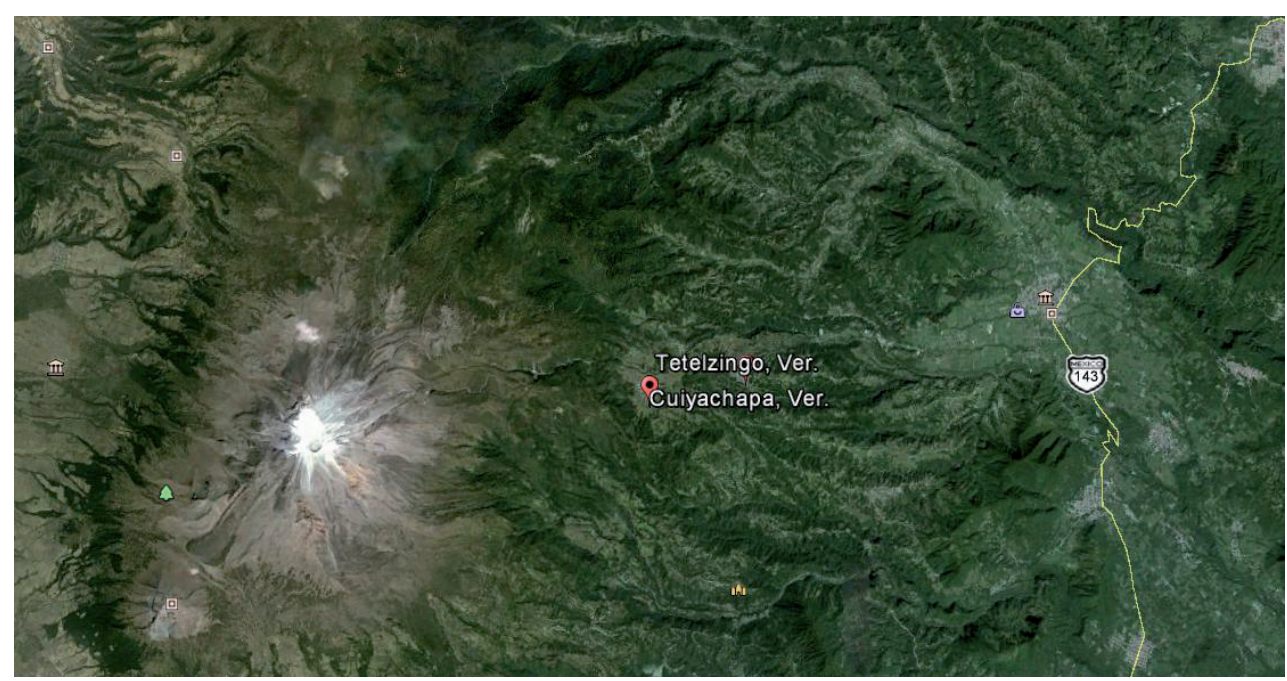

Fig. 2. Volcán Citlaltépetl y los poblados de Cuiyachapa y Tetelcingo.

Fig. 2. Citlaltépetl Volcano and the villages of Cuiyachapa and Tetelcingo.

\section{MATERIALES Y MÉTODOS}

Para este análisis fue necesario conocer las características geomorfológicas del Volcán Citlaltépetl con apoyo de mapas, fotos aéreas e imágenes satelitales de dicha región, identificándose algunos factores de intemperismo que afectan la zona de estudio, así como algunas características geomorfológicas y tipos de relieve que pudieran generar algún tipo de amenaza y riesgo, principalmente deslizamiento de laderas y flujos en algunas de las barrancas Ojo Salado y Seca (CORTÉS et al. 2012).
Se identificaron las geoformas como punto de referencia de las barrancas Ojo Salado y Seca, así como el ángulo de inclinación de la línea base entre dos pendientes, además de obtener datos cartográficos referenciales (Fig. 3). Se identificaron las vertientes y valles que pudiesen ser funcionales a la dinámica de fusión del glaciar Jamapa en el Volcán Citlaltépetl y a eventos pluviométricos que afecten a las localidades pobladas antes mencionadas (Fig. 4).

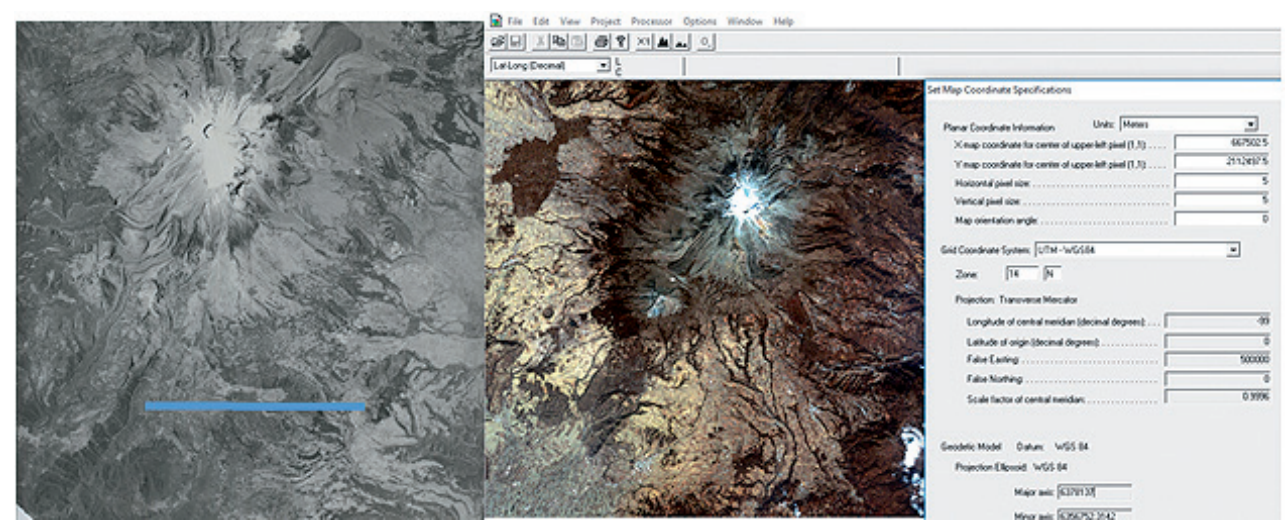

Fig. 3. Línea base (color aZul) para referenciar las barrancas OJo Salado y Seca.

Fig. 3. Baselina (blue) to Reference Ojo Salado and Seca canyons. 


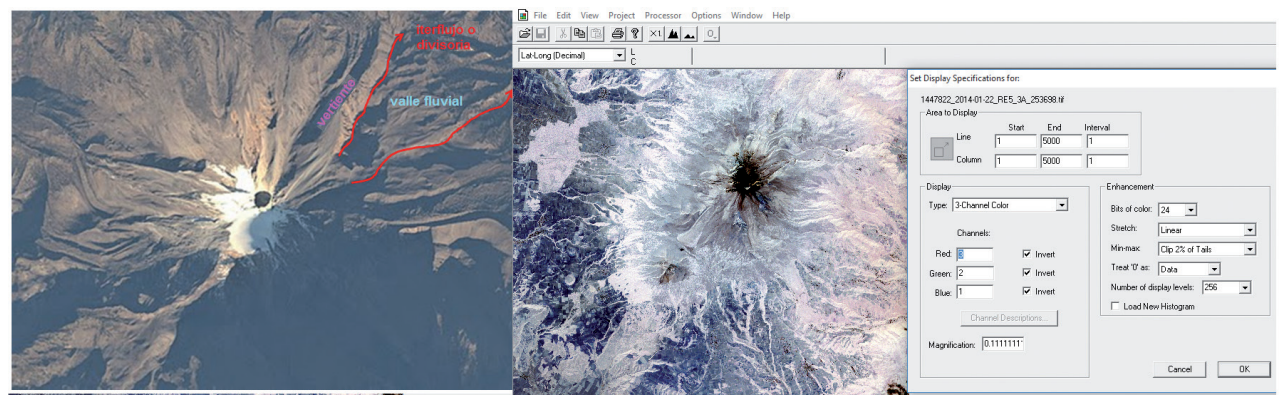

Fig. 4. IdENTIFICACIÓN de LaS CARACTERÍSTICAS GEOMORFOLÓGICAS EXISTENTES EN LA ZONA DE

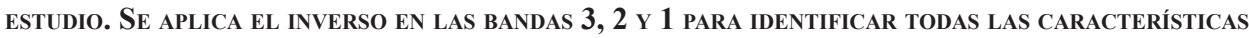
ESTRUCTURALES DE ESCURRIMIENTOS EN LAS BARRANCAS.

Fig. 4. IDENTIFICATION OF EXISTING GEOMORPHOLOGY IN THE STUDY AREA, THE REVERSE APPLIES IN BANDS 3, 2, 1 TO IDENTIFY ALL STRUCTUCTURAL CHARACTERISTICS OF RUNOFF IN THE CANYONS.

Las barrancas representan un tipo de desplazamiento vertical, una falla normal cuyo bloque de techo se desplaza hacia abajo. La mayoría tiene buzamientos de unos $60^{\circ}$ que tienden a disminuir con la profundidad; algunas fallas con desplazamiento vertical tienen buzamientos menores, aproximándose a la horizontal (ONTIVEROS et al. 2015). Debido a la altitud del volcán se determinó el perfil y el DEM para localizar las pendientes más pronunciadas que representan un mayor riesgo (figuras 5 y 6 ).

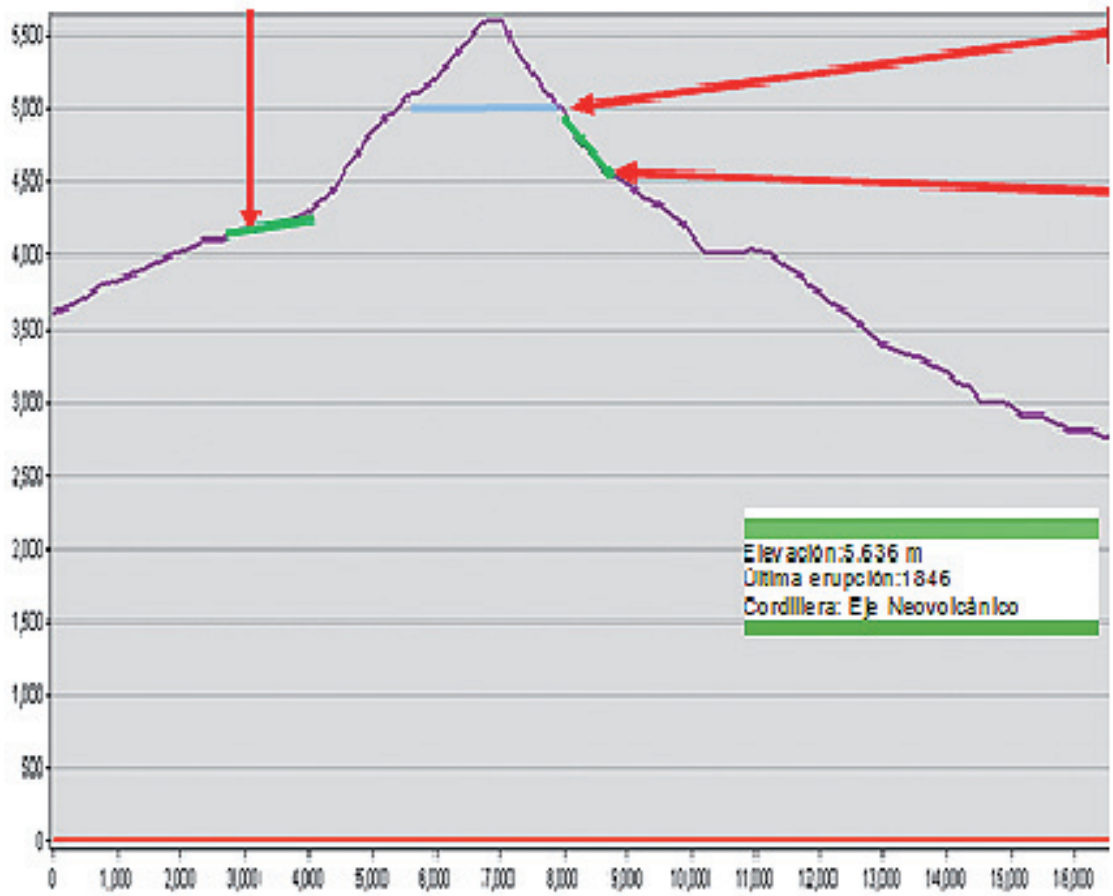

Fig. 5. Perfil obtenido de forma georreferencial para determinar la altura.

Fig. 5. GEO-REFERENTIAL PROFILE OBTAINED TO DETERMINE HEIGHT. 


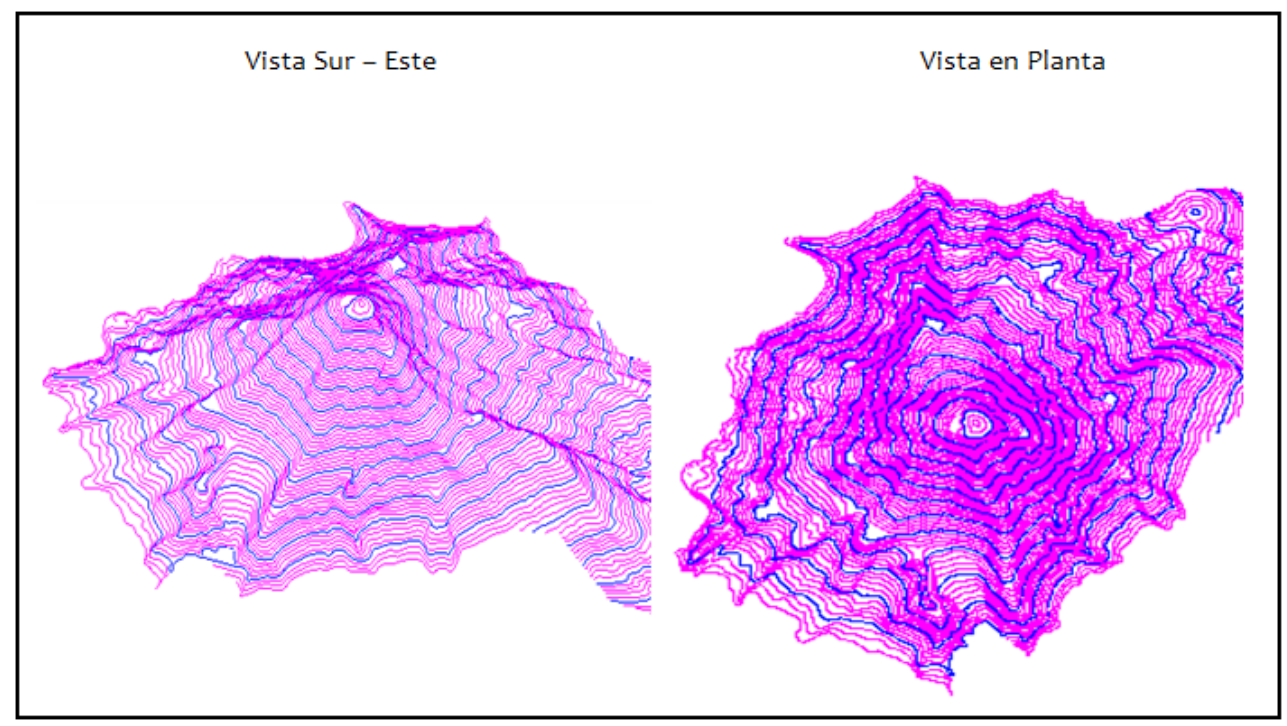

Fig. 6. Mapa digital.

Fig. 6. Digital MaP.

Para calcular la presión atmosférica de todas las barrancas se aplicó el modelo 1976 Standard Atmosphere Calculator, arrojando un valor de 495.839735 milibars (Fig. 7). Con el programa Gravity information system of ptb se cálculo la aceleración de la gravedad local en cada punto de las barrancas (Fig. 8). Los datos con los que se alimentaron los programas antes mencionados se presentan en la Tabla 1 para la barranca Ojo Salado.

\section{Standard Atmosphere Calculator}

\begin{tabular}{|l|l|}
\hline Input & \\
\hline Altitude: & meters [m] \\
Temperature offset ${ }^{*}: 0$ & Celsius / Kelvin \\
-Temperature deviation from 1978 standard atmosphere (off-standard atmosphere). \\
\hline
\end{tabular}

\begin{tabular}{|c|c|c|c|c|c|}
\hline \multicolumn{6}{|l|}{ Output } \\
\hline Temperature: & 251.516 & Kelvin & $\rightarrow$ & & \\
\hline Pressure: & 495.839735 & \multicolumn{3}{|c|}{ millibars } & - \\
\hline Density: & 0.686774 & \multicolumn{3}{|c|}{ kilograms/cubic meter } & \\
\hline Speed of sound: & 317.927336 & \multicolumn{3}{|c|}{ meters/second [m/s] } & \\
\hline
\end{tabular}

Fig. 7. Resultados de la aplicación del programa 1976 Standard Atmosphere Calculator.

Fig. 7. Results of the program 1976 Standard Atmosphere Calculator. 


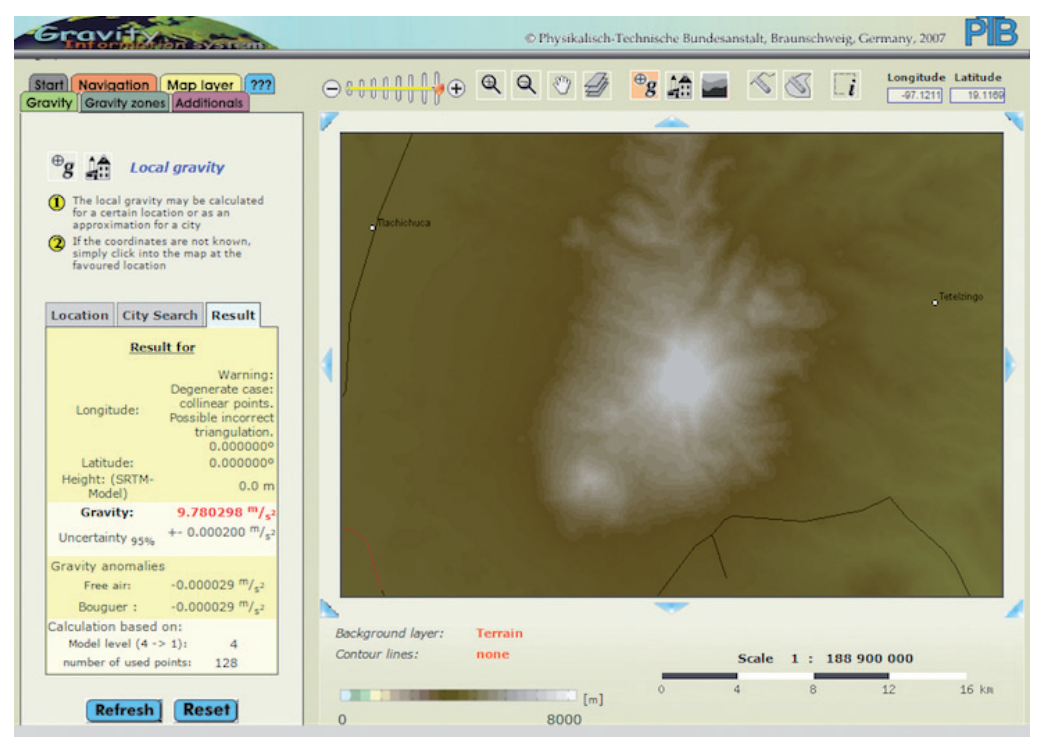

Fig. 8. Resultados del programa GRaVity INFormation SyStem of Ptb, PARA EL CÁlculo de la ACELERACIÓN DE LA GRAVEDAD.

Fig. 8. Results of the Gravity Informations System program of PTB, to calculate the ACCELERATIONS OF GRAVITY AT THE POINTS OF THE STUDY AREA.

\section{Análisis fotogramétrico}

\section{Barranca Ojo Salado}

En la tabla 1 se muestran los datos que sirvieron para calcular la aceleración de la gravedad y presión de la barranca Ojo
Salado (fig. 9 y 10), con los programas arriba mencionados (RAMOS et al. 2008).

TABla 1. LATITUd, LONGITUd, ALTURA, ACELERACión de LA GRAVEDAD Y PRESIÓN DE LOS PUNTOS INICIAL, MEDIO Y FINAL.

TABle 1. LATITUde, LONGITUde, HIEGHT, ACCELERATION OF GRAVITY AND PRESSURE OF THE INITIAL, MIDDLE AND END POINTS.

\begin{tabular}{|c|c|c|c|c|}
\hline \multicolumn{5}{|l|}{ Pico de Orizab a } \\
\hline Latitud & Longitud & Altura & $\begin{array}{c}\text { Aceleración de la } \\
\text { Gravedad }\end{array}$ & Presión \\
\hline $19^{\circ} 01^{\circ} 48^{\prime \prime}$ & $97^{\circ} 16^{\prime} 04.8^{\prime \prime}$ & $5636 \mathrm{~m}$ & $9.771697 \mathrm{~m} / \mathrm{s}^{2}$ & $495.839735(\mathrm{hPA})$ \\
\hline \multicolumn{5}{|c|}{ Barranca Ojo Salad o ( $8 \mathrm{~km}$ ) } \\
\hline \multicolumn{5}{|l|}{ Punto Inicial } \\
\hline $19^{\circ} 02^{\prime} 05.52^{\prime \prime}$ & $97^{\circ} 16^{\prime} 00.54^{\prime \prime}$ & $5313 \mathrm{~m}$ & $9.772713 \mathrm{~m} / \mathrm{s}^{2}$ & $517.983539(\mathrm{hPA})$ \\
\hline \multicolumn{5}{|l|}{ Punto Medio } \\
\hline $19^{\circ} 02^{\prime} 44.32^{\prime \prime}$ & $97^{\circ} 14^{\prime} 19.21^{\prime \prime}$ & $3889 \mathrm{~m}$ & $9.776350 \mathrm{~m} / \mathrm{s}^{2}$ & $625371260(\mathrm{hPA})$ \\
\hline \multicolumn{5}{|l|}{ Punto Final } \\
\hline $19^{\circ} 03^{\circ} 00.22^{\prime \prime}$ & $97^{\circ} 12^{\prime} 24.87^{\prime \prime}$ & $3223 \mathrm{~m}$ & $9.779110 \mathrm{~m} / \mathrm{s}^{2}$ & $681.430956(\mathrm{hPA})$ \\
\hline
\end{tabular}



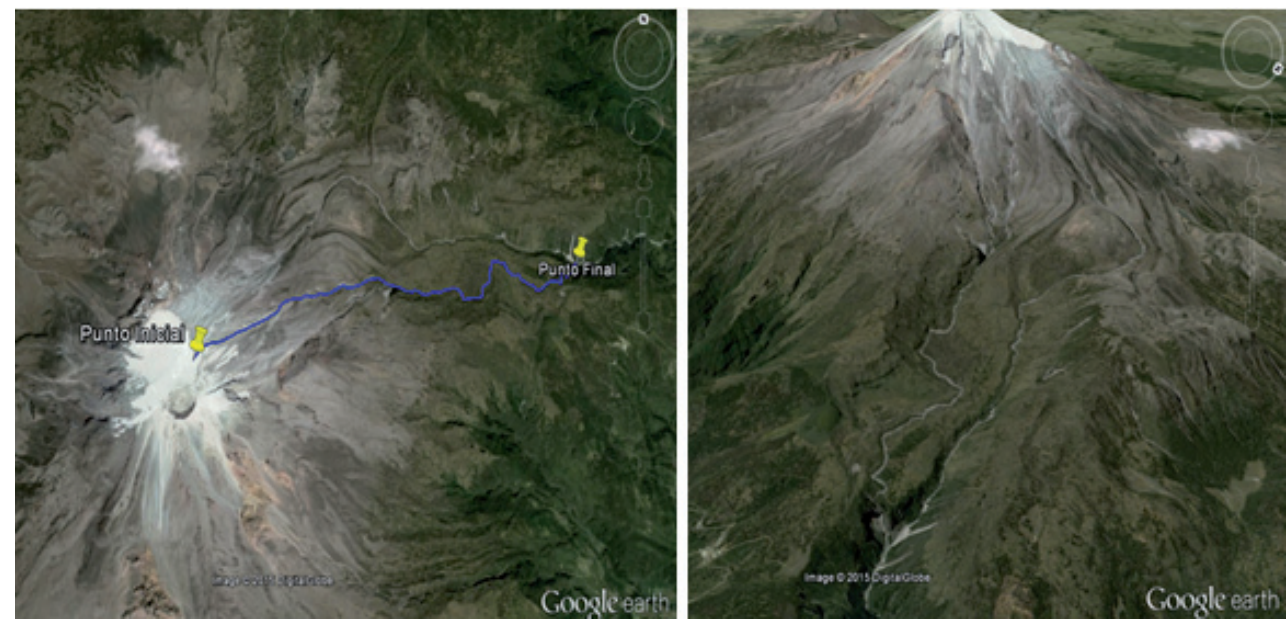

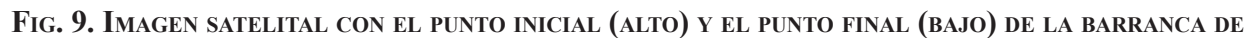
ESTUDIO.

Fig. 9. Satellite image with starting point (high) and end point (bass) Study Canyon.

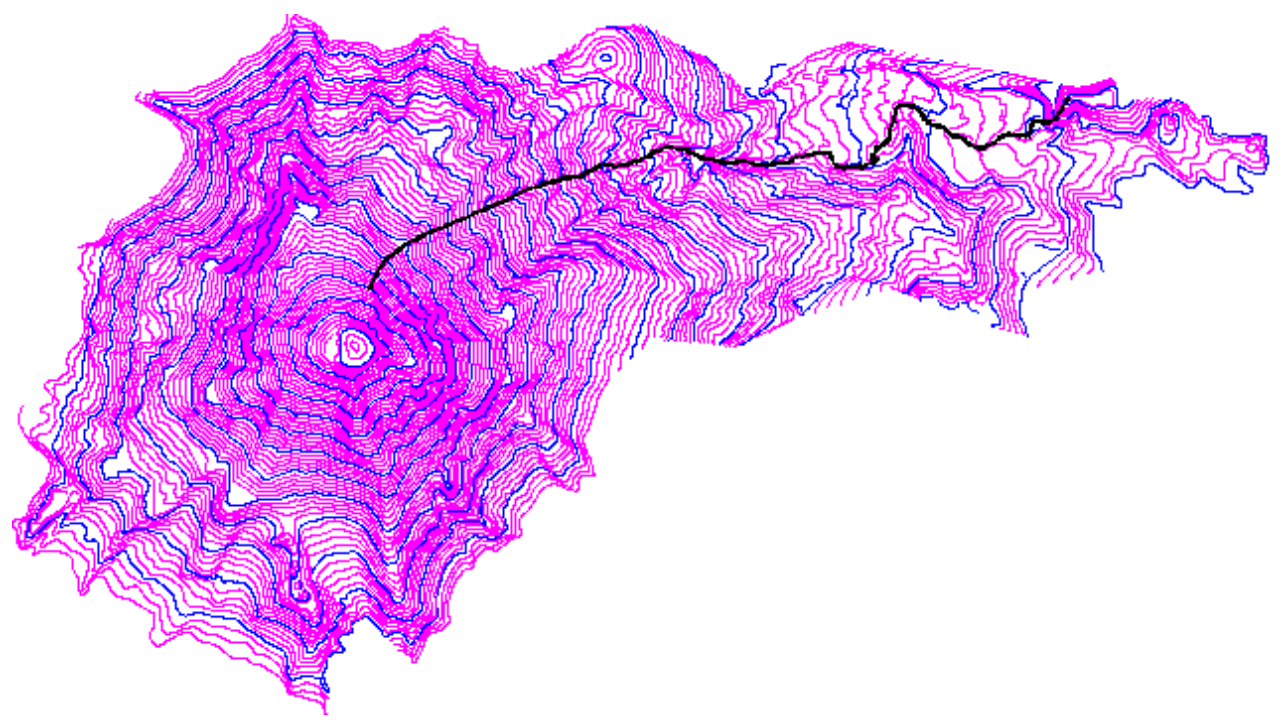

Fig. 10. Modelo digital de la zona de estudio.

Fig. 10. Digital model of THE STUdy zone.

\section{Barranca Seca}

Para el análisis de esta barranca se utilizó la foto satelital (Fig. 11), luego se capturaron las capas de alturas (Fig. 12) y se realizó el perfil topográfico (fig. 13), que generó los datos de la tabla 2 tanto para el Volcán Citlaltépetl como para la Barranca Seca. 


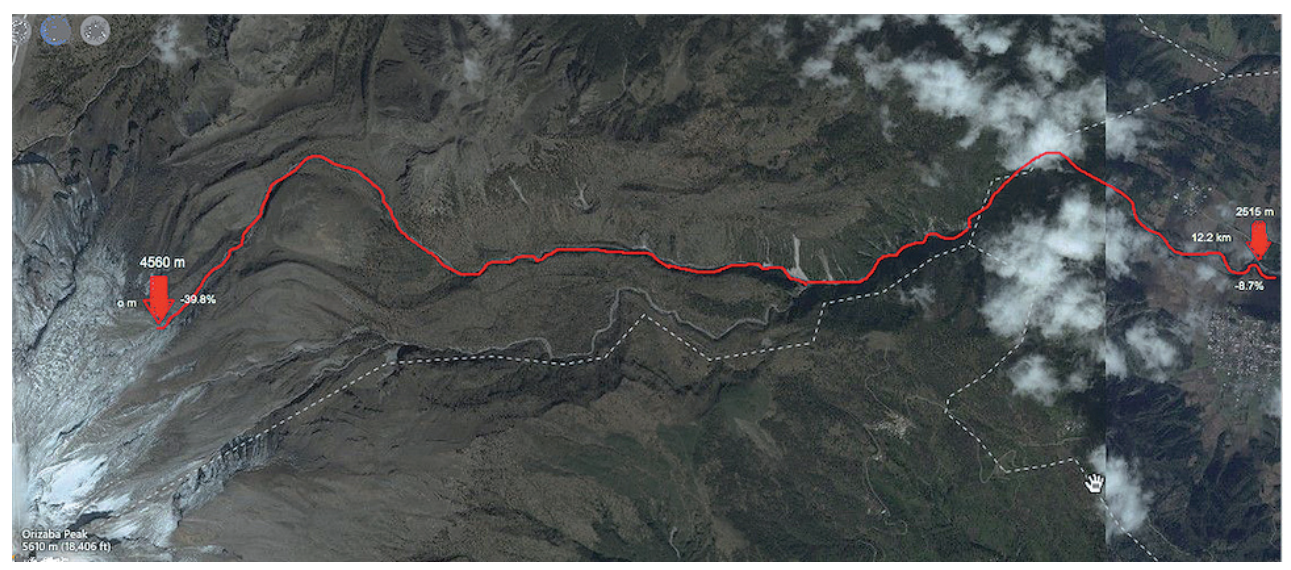

Fig. 11. UBiCACIÓN de LA BARRANCA, PUNTO MÁXIMO 4.560 M.S.N.M, PUNTO MíNIMO 2.515 M.S.N.M, LONGITUD 12.2 KM. Y PENDIENTE PROMEDIO DE $30 \%$.

Fig. 11. Location CANYON, PEAK POINT 4,560 M.A.S.L., Minimum POINT 2,515 M.A.S.L., LENGTH 12.2 KM, AVERAGE GRADIENT $30 \%$.

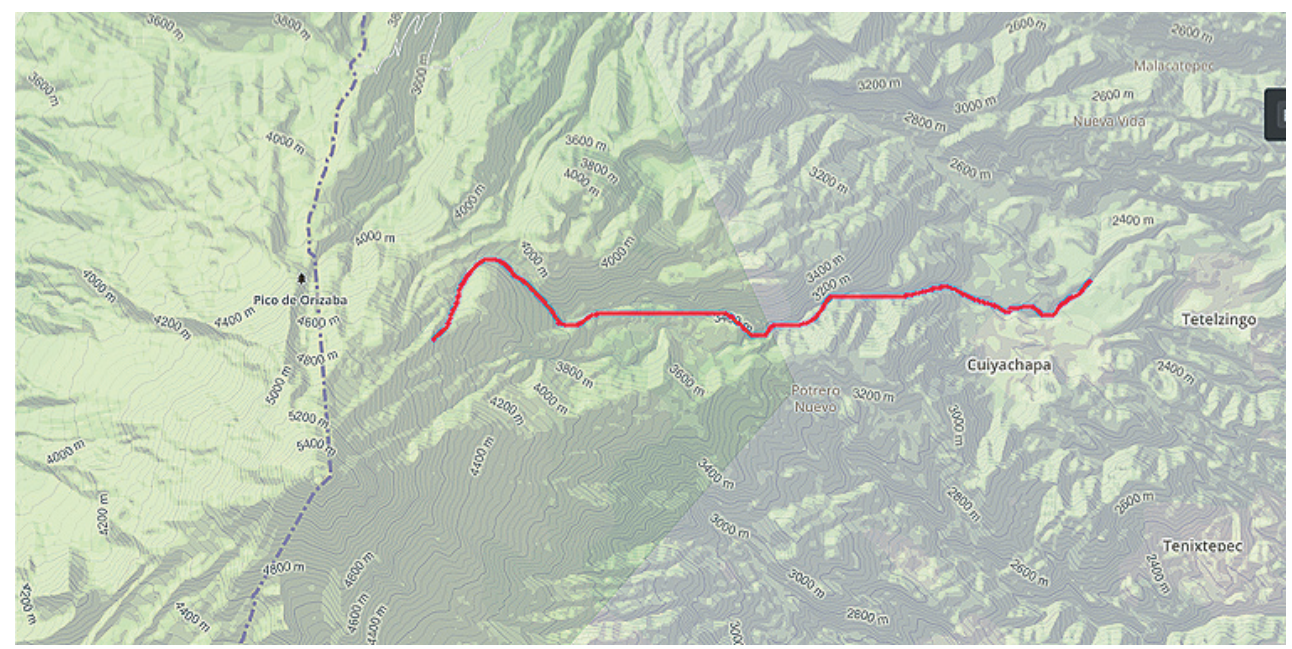

Fig. 12. UBICACIÓN de LA BARRANCA EN FORMATO DIGITAL: CURVAS DE NIVEL DE 100 M.

Fig. 12. Location CANYON IN DigItAL fORMat: CONTOUR LiNES 100 M.

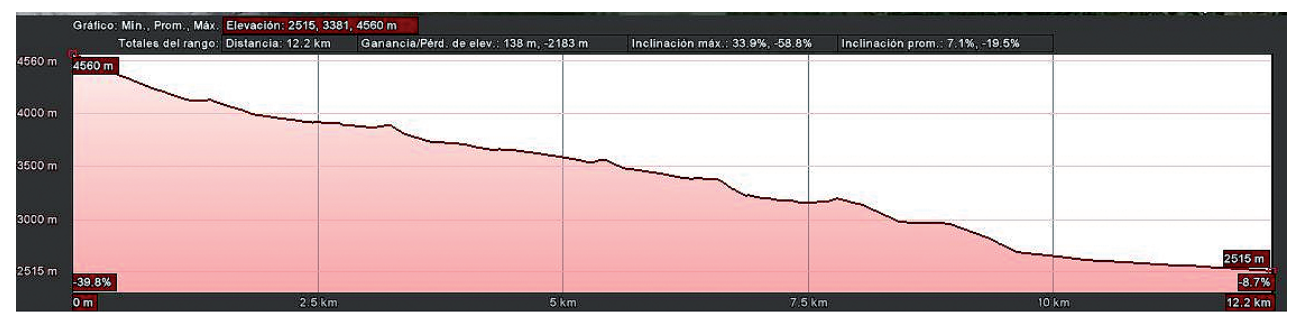

Fig. 13. Perfil topográfico.

Fig. 13. TOPOGRAPHIC PROFILE. 
Tabla 2. CoOrdenadas geográficas, aCEleración de la graVedad (Modelo SiSproject), Altura y PResión (Modelo Digital Dutch).

Table 2. Geographical coordinates, acceleration of gravity ( SISproject Model), height and pressure (Dutch Digital Model).

\begin{tabular}{|c|c|c|c|c|c|c|c|c|c|c|}
\hline \multicolumn{4}{|c|}{$\begin{array}{l}\text { Coordenadas Geográficas } \\
\text { Volcán: Pico de Orizaba }\end{array}$} & & & & & \multirow{3}{*}{ Altura(m) } & \multirow{3}{*}{$\begin{array}{c}\text { Gravedad } \\
\mathrm{m} / \mathrm{s}^{2}(\mathrm{PTB})\end{array}$} & \multirow{3}{*}{$\begin{array}{c}\text { Presión } \\
\text { (milibares) }\end{array}$} \\
\hline \multicolumn{4}{|c|}{ Longitud (x) } & \multicolumn{4}{|c|}{ Latitud (y) } & & & \\
\hline$\circ$ & ' & $"$ & Sexadecimal & - & ' & $"$ & Sexadecimal & & & \\
\hline-97 & 16 & 4.8 & -97.268 & \begin{tabular}{|l|}
19 \\
\end{tabular} & 1 & 48 & 19.0300 & 5577.0000 & \begin{tabular}{l|l}
9.771890 & 4
\end{tabular} & 499.82627 \\
\hline \multicolumn{11}{|c|}{$\begin{array}{l}\text { Coordenadas Geográficas: } \\
\text { B arranca Seca parte alta }\end{array}$} \\
\hline \multicolumn{4}{|c|}{ Longitud (x) } & \multicolumn{5}{|c|}{ Latitud (y) } & \multirow{2}{*}{$\begin{array}{c}\text { Gravedad } \\
\mathrm{m} / \mathrm{s}^{2} \\
\text { (PTB) }\end{array}$} & \multirow{2}{*}{$\begin{array}{l}\text { Presión } \\
\text { (milibares) }\end{array}$} \\
\hline 。 & 1 & $"$ & Sexadecimal & 。 & ' & $"$ & Sexadecimal & Altura(m) & & \\
\hline-97 & & \begin{tabular}{l|l}
5 & 21.7
\end{tabular} & -97.256 & 19 & 2 & 49.33 & 19.0470 & 4560.0000 & 9.774732 & 572.72733 \\
\hline \multicolumn{4}{|c|}{$\begin{array}{l}\text { Coordenadas Geográficas: } \\
\text { B arranca Seca parte baja }\end{array}$} & \multicolumn{4}{|c|}{ ・ } & \multicolumn{3}{|r|}{. } \\
\hline \multicolumn{4}{|c|}{ Longitud (x) } & \multicolumn{4}{|c|}{ Latitud (y) } & \multirow[b]{2}{*}{$\operatorname{Altura}(\mathrm{m})$} & \multirow{2}{*}{$\begin{array}{c}\text { Gravedad } \\
\mathrm{m} / \mathrm{s}^{2} \\
\text { (PTB) }\end{array}$} & \multirow{2}{*}{$\begin{array}{l}\text { Presión } \\
\text { (milibares) }\end{array}$} \\
\hline$\circ$ & 1 & $"$ & Sexadecimal & $\therefore$ & 1 & $"$ & Sexadecimal & & & \\
\hline \begin{tabular}{l|}
-97 \\
\end{tabular} & 9 & 46.81 & -97.163 & 19 & 3 & 18.56 & 19.0552 & 2515.0000 & 9.779336 & 745.41887 \\
\hline \multicolumn{8}{|c|}{$\begin{array}{l}\text { Coordenadas Geográficas: } \\
\text { B arranca Seca parte media }\end{array}$} & & & \\
\hline \multicolumn{4}{|c|}{ Longitud (x) } & & \multicolumn{3}{|c|}{ Latitud (y) } & \multirow{2}{*}{$\operatorname{Altura}(\mathrm{m})$} & \multirow{2}{*}{$\begin{array}{l}\text { Gravedad } \\
\mathrm{m} / \mathrm{s}^{2} \text { (PTB) }\end{array}$} & \multirow{2}{*}{$\begin{array}{c}\text { Presión } \\
\text { (milibares) }\end{array}$} \\
\hline 8 & 1 & $" 1$ & Sexadecimal & 8 & 1 & $"$ & Sexadecimal & & & \\
\hline-97 & 13 & 16.85 & -97.221 & 19 & 3 & 8.53 & 19.0524 & 3537.0000 & 9.777122 & 654.51469 \\
\hline
\end{tabular}

La figura 14 expresa el comportamiento de la aceleración de la gravedad para la barranca, que fue obtendio procesando y modelando en 2D y 3D. La gravedad obtenida indica que no existe depresión. 


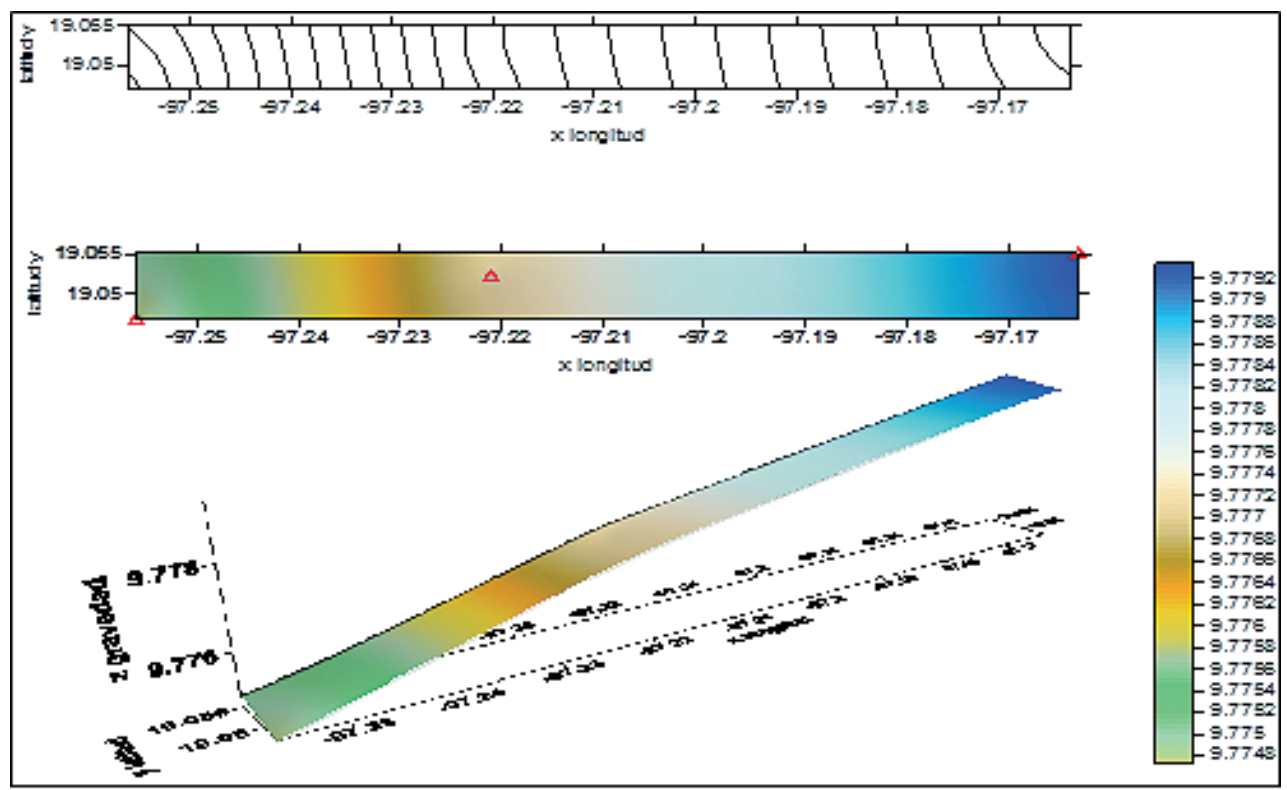

Fig. 14. Modelamiento 2D y 3D y ACELERACión de LA GRAVEDAD.

Fig. 14. Via 2D AND 3D MOdeling AND THE ACCELERATION OF GRAVITY OF EACH POINT.

Para determinar el desnivel entre puntos se utilizó la correlación distancia-foto de la zona de estudio, a través de paralajes con desarrollo de profundidad que sirvieron como datos para los cálculos matemáticos posteriores (Fig. 15), realizados para encontrar las coordenadas de un punto $\mathrm{C}$ dentro de la barranca, con el objetivo de generar datos de puntos determinados en la zona de estudio como referencia de lecturas de los datos arriba obtenidos (Tabla 3).

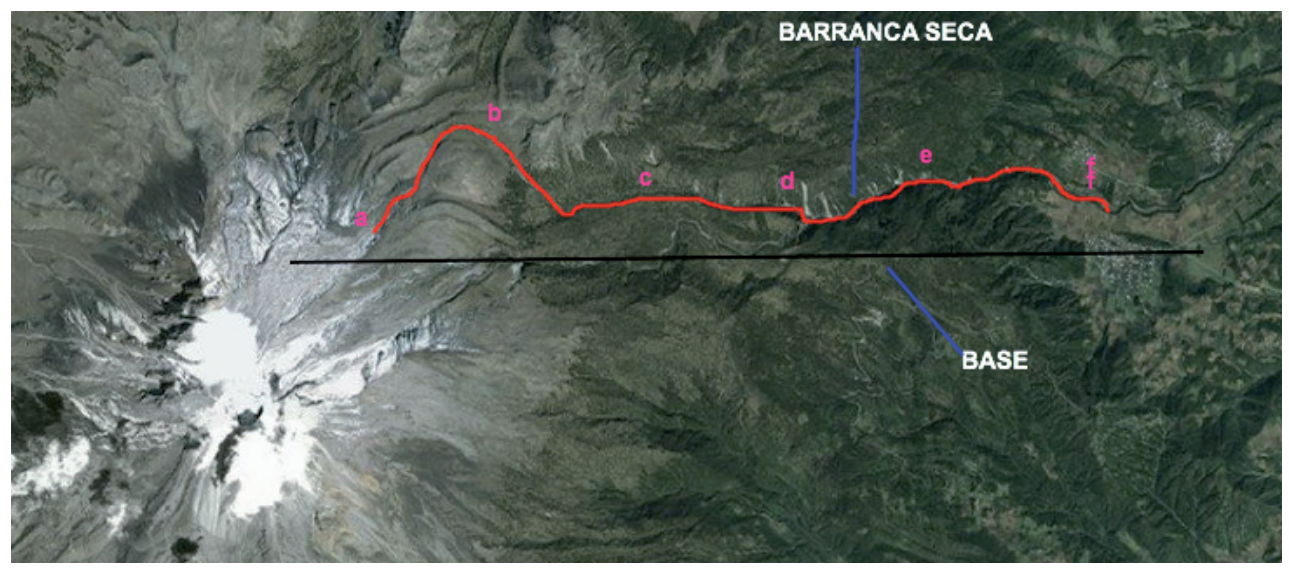

Fig. 15. Distancias aB, BC, CD, DE Y EF.

Fig. 15. Distance AB, BC, CD, DE Y EF. 
Tabla 3. Cálculo de CoOrdenadas en la barranca.

Table 3. Calculation of coordinates in Canyon.

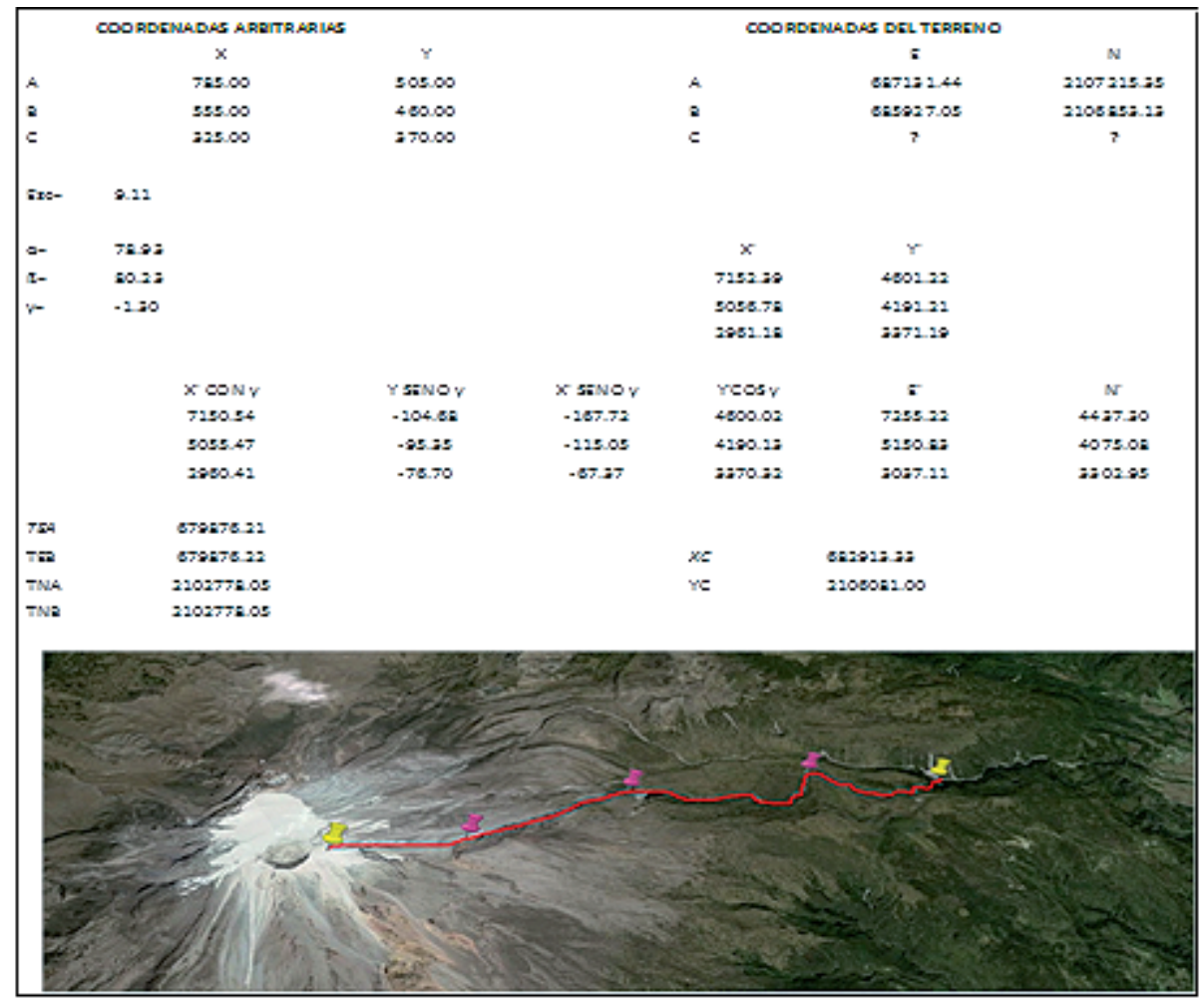

Análisis geoestadístico

La figura 16 muestra la gráfica de regresión entre la altura y presión aplicando el programa GEOEAS (Geoestatistical
Enviromenal Assessment Software) y la figura 17 muestra la gráfica de regresión entre la altura y aceleración de la gravedad.

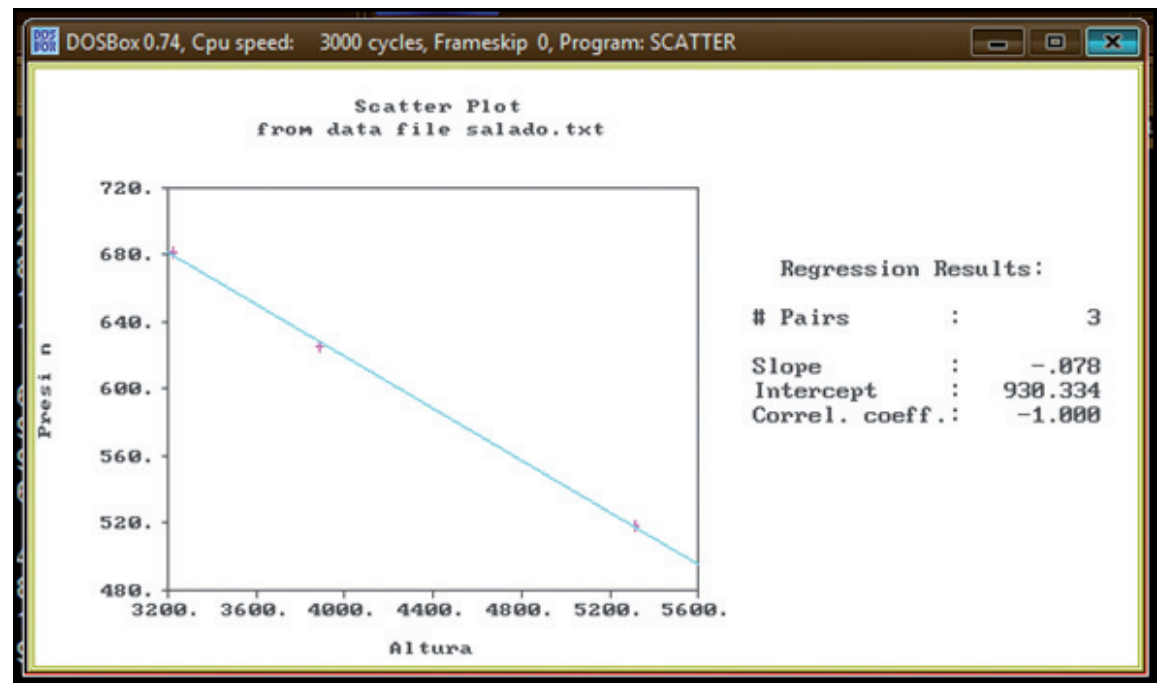

FIG. 16. COEFICIENTE DE CORRELACIÓN DE LA ALTURA Y PRESIÓN.

Fig. 16. Correlation COEFFicient height AND PRESSURE. 


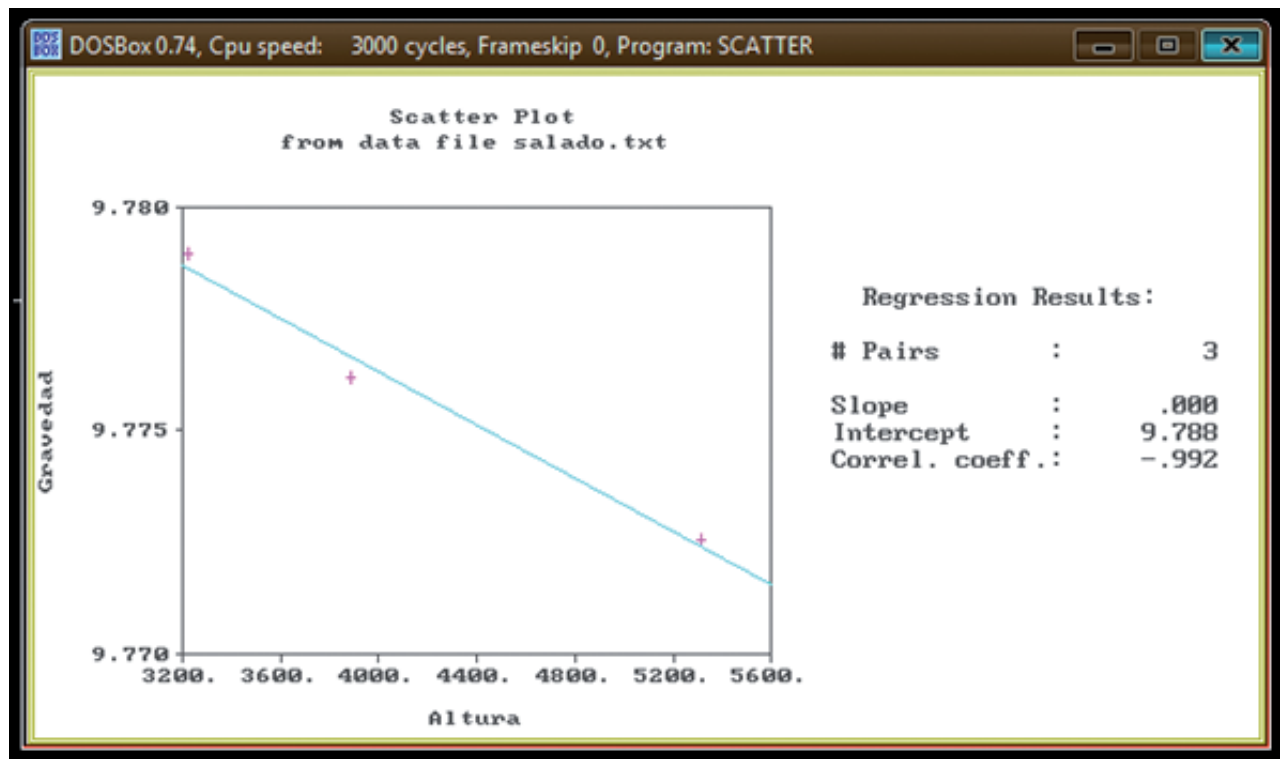

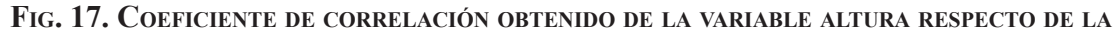
ACELERACIÓN DE LA GRAVEDAD.

Fig. 17. CORRELATION COEFFICIENT VARIABLE HEIGHT WITH RESPECT TO THE ACCELERATION OF GRAVITY.

\section{Modelo estructural}

Aplicando el programa Surfer (Fig. 18), se determina el comportamiento de las variables procesadas en $2 \mathrm{D}$ y $3 \mathrm{D}$ de la presión (izquierda) y aceleración de la
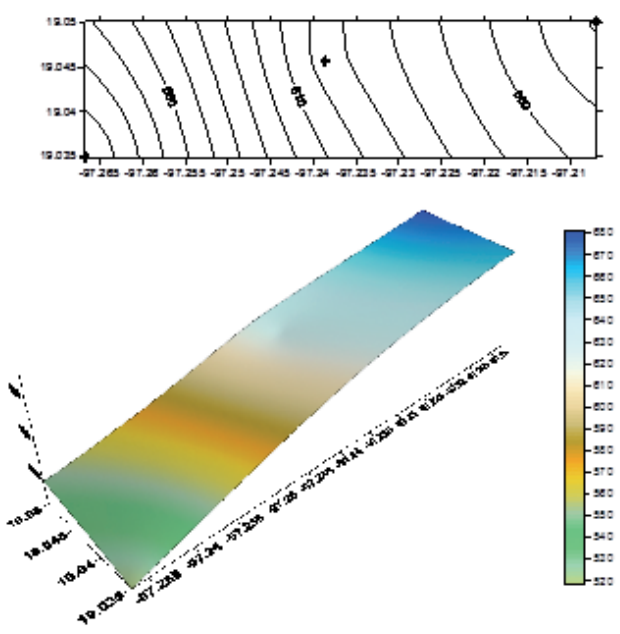

gravedad (derecha), según RAMOS et al. (2009). Se realizó la cartografía de la zona de estudio modelándose las curvas de nivel de cada barranca en coordenadas UTM, para determinar el comportamiento vectorial de las barrancas analizadas (Fig. 19).
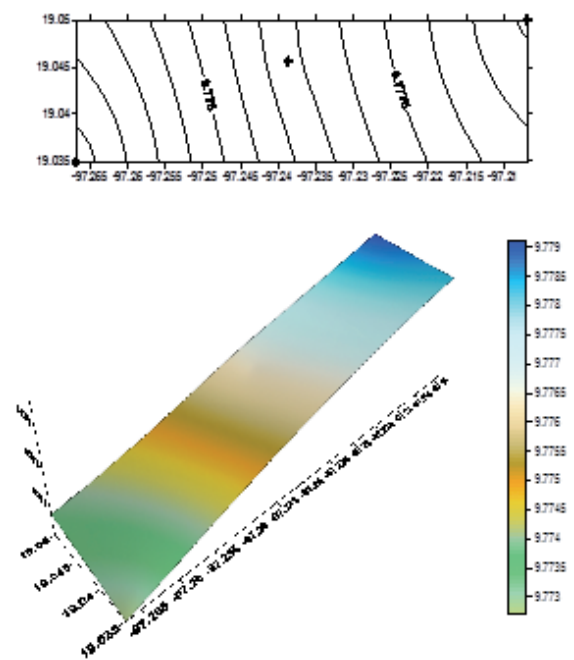

Fig. 18. Modelación del COMPORTAMiento de La PREsión Y ACELERACión de LA GRAVEDAd de LA barRanca OJo Salado.

Fig. 18. Modeling of the behavior of pressure and gravity acceleration OJo Salado Canyon. 


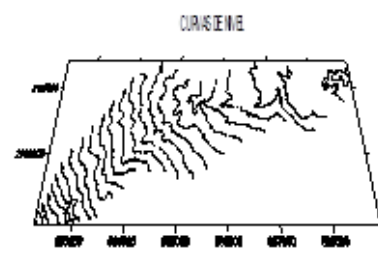

RTELI PBTIS
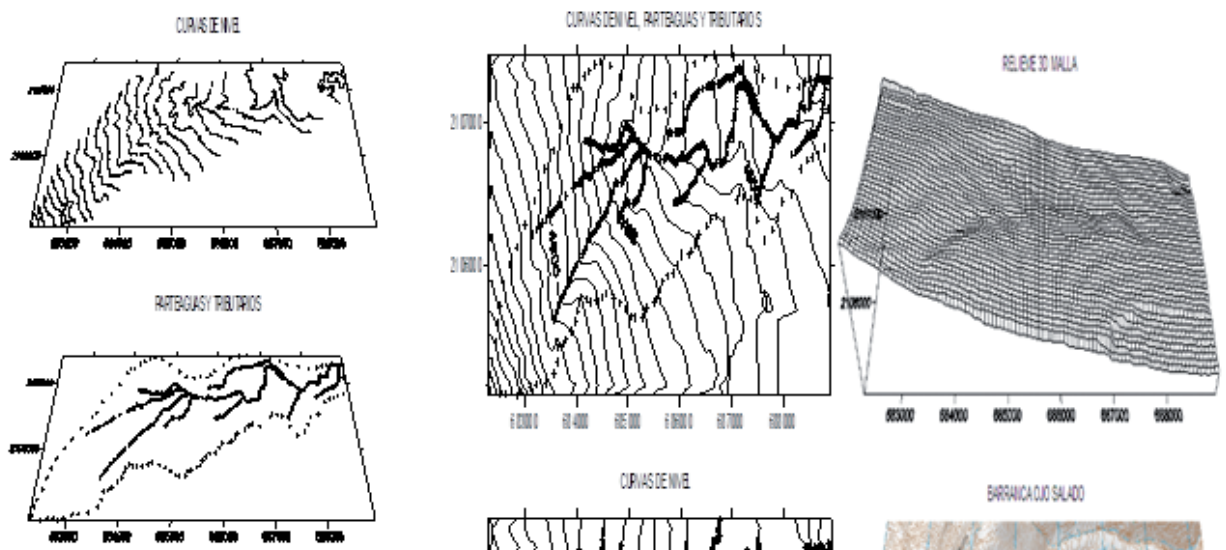

PAOT TPMPEF ID
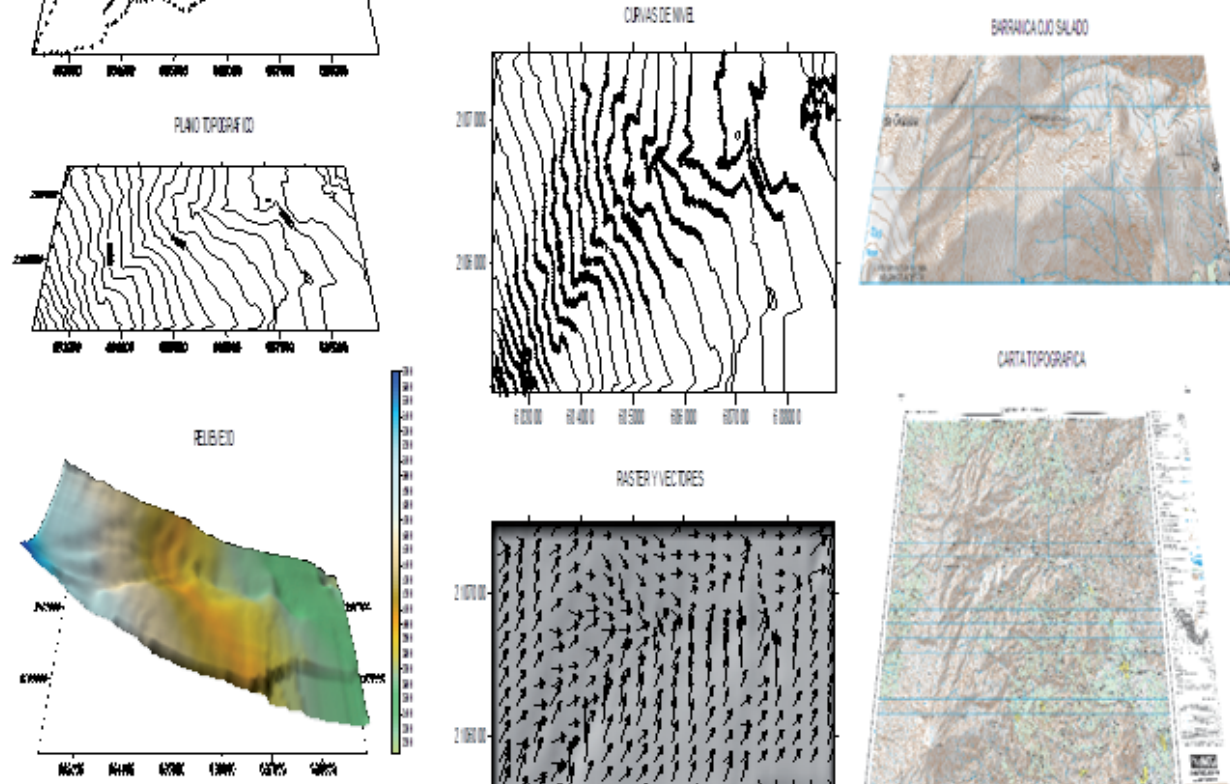

PNEPYIELTES
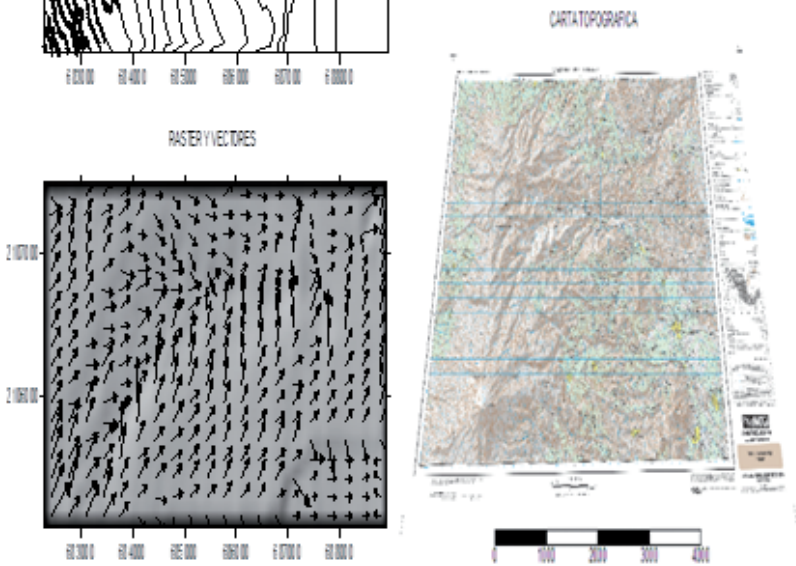

Fig. 19. Modelación de LaS CuRVas de NIVEL.

Fig. 19. Modeling of Contour Lines.

\section{Cálculos fotogramétricos}

Para determinar el desnivel de la barranca se calculó, mediante el método de escala fotográfica, la escala media de la zona y su discrepancia (Tabla 2). Se obtuvieron las medidas de la foto y del terreno y se logró la escala media que para este caso fue de $1: 100.000$ y una discrepancia de $0,035 \%$. La tabla 4 muestra los cálculos para la determinación del desnivel de la barranca, utilizando fotos aéreas. 


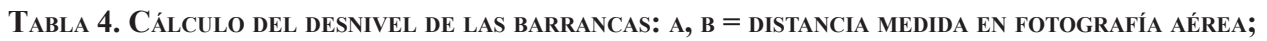
C, D = distancia de Fotografía aÉrea; A, B = distancia de terreno; $\mathbf{C}, \mathbf{D}=$ distancia de terreno.

Table 4. Calculation Canyon Slope: a, B = distance in aerial Photography; C, $D=$ distance in AERIAL PHOTOGRAPHY; A,B = DisTANCE FROM GROUND; C = DISTANCE OF GROUND.

\begin{tabular}{|c|c|}
\hline E scala de la Fotografía & \\
\hline Datos & Medidas en Foto \\
\hline$a b=$ & $0.015 \mathrm{~mm}$ \\
\hline$c d=$ & $0.024 \mathrm{~mm}$ \\
\hline Datos & Medidas en el Terreno \\
\hline$A B=$ & $1334 \mathrm{~mm}$ \\
\hline $\mathrm{CD}=$ & $2210 \mathrm{~mm}$ \\
\hline $\begin{aligned} & \text { Escala } \\
= & \end{aligned}$ & $\frac{1}{A B / a b}$ \\
\hline$E_{1=}$ & $\frac{1}{88933.33333}$ \\
\hline$E_{2=}$ & $\frac{1}{C D / c d}$ \\
\hline$E_{2=}$ & $\frac{1}{92083.33333}$ \\
\hline Distancia & $\frac{\left(E_{1-} E_{2}\right)}{\left(E_{1-} E_{2}\right) / 2}$ \\
\hline$D=$ & $\frac{-3150.00000}{98508.33333}$ \\
\hline$D=$ & 0.03480 \\
\hline
\end{tabular}




\section{RESULTADOS Y CONSIDERACIONES FINALES}

A través de mediciones micrométricas esteroscópicas se pudo establecer que las barrancas analizadas presentan un movimiento fundamental de dirección paralela al buzamiento de la superficie, asociado a la falla con desplazamiento vertical. Este tipo de movimiento puede producir pequeños resaltes o escarpes debido al desplazamiento que genera la sismicidad volcánica.

Se pone de manifiesto la importancia de la aplicación de métodos fotogramétricos en las ciencias de la tierra en temas asociados a la vulnerabilidad de poblados en las laderas del Volcán Citlaltépetl, vinculado a la actividad de dos barrancas que drenan junto a los poblados de Cuiyachapa y Tetelcingo. La aceleración de la gravedad, la presión y la modelación en 2D y 3D, correlacionando los datos con modelos fotogeomorfológicos para determinar las escalas del mapa y del terreno, así como los desniveles de las mismas utilizando puntos de apoyo, permitieron conocer la dinámica de estos barrancos frente a la activación de éstos por la acción pluvial o de deshielo glacial. A este respecto, el aumento de la temperatura parece ser la causa dominante, aunque no la única, del retroceso del glaciar en el Volcán Citlaltépetl o Pico de Orizaba. En el escenario actual de cambios climáticos, el glaciar continuará retrocediendo, no obstante haya un aumento de la precipitación a escala local. Los cambios observados en la estructura volcánica y del glaciar se relacionan con la actividad magmática y las constantes modificaciones térmicas y eólicas ocasionadas por el cambio climático en los últimos 20 años, lo que ha dado lugar a la topografía existente en la zona. Los resultados obtenidos son la base de estudios posteriores de carácter geohidrológico en las barrancas Ojo Salado y Seca.

\section{REFERENCIAS}

RAMOS, R., P. MÁXIMO, B. SOTO, S. ALCÁNTARA \& M. VÁZQUEZ, 2014. Análisis geoestadístico de las barrancas Colorada y Quimichule del volcán Popocatépetl (México), como aporte a la prevención de desastres naturales. Investigaciones Geográficas, 47: 67-82.

CORTÉS, J. \& H. DELGADO, 2012. The recent retreat of Mexican glaciers on Citlaltépetl Volcano detected using ASTER data. The Cryosphere Discussions, 6: 31-49.

PALACIOS, D. \& L. VÁZQUEZ, 1996. Geomorphic Effects of the Retreat of Jamapa Glacier, Pico de Orizaba Volcano (México). Geografiska Annaler. Series A Physical Geography, 78: 19-34.

ONTIVEROS-GONZÁLEZ, G., H. DELGADO \& J. CORTÉS, 2015. Surface Energy Balance model for high-altitude glacial system at $19^{\circ} \mathrm{N}$ on Glaciar Norte, Mexico, Geofísica Internacional, 54-4: 299314.

RAMOS, R., P. MÁXIMO, B. MONTIEL, Y. GONZÁLEZ \& A. RODRÍGUEZ, 2008. Análisis fotogramétrico del volcán Citlaltépetl. Cartográfica, 84: 105-116.

RAMOS, R., P. MÁXIMO, Y. GONZÁLEZ \& B. MONTIEL, 2009. Monitoreo y vigilancia del volcán Citlaltépetl o Pico de Orizaba (análisis geomorfológico). Geofísica, 61: 33-45. 


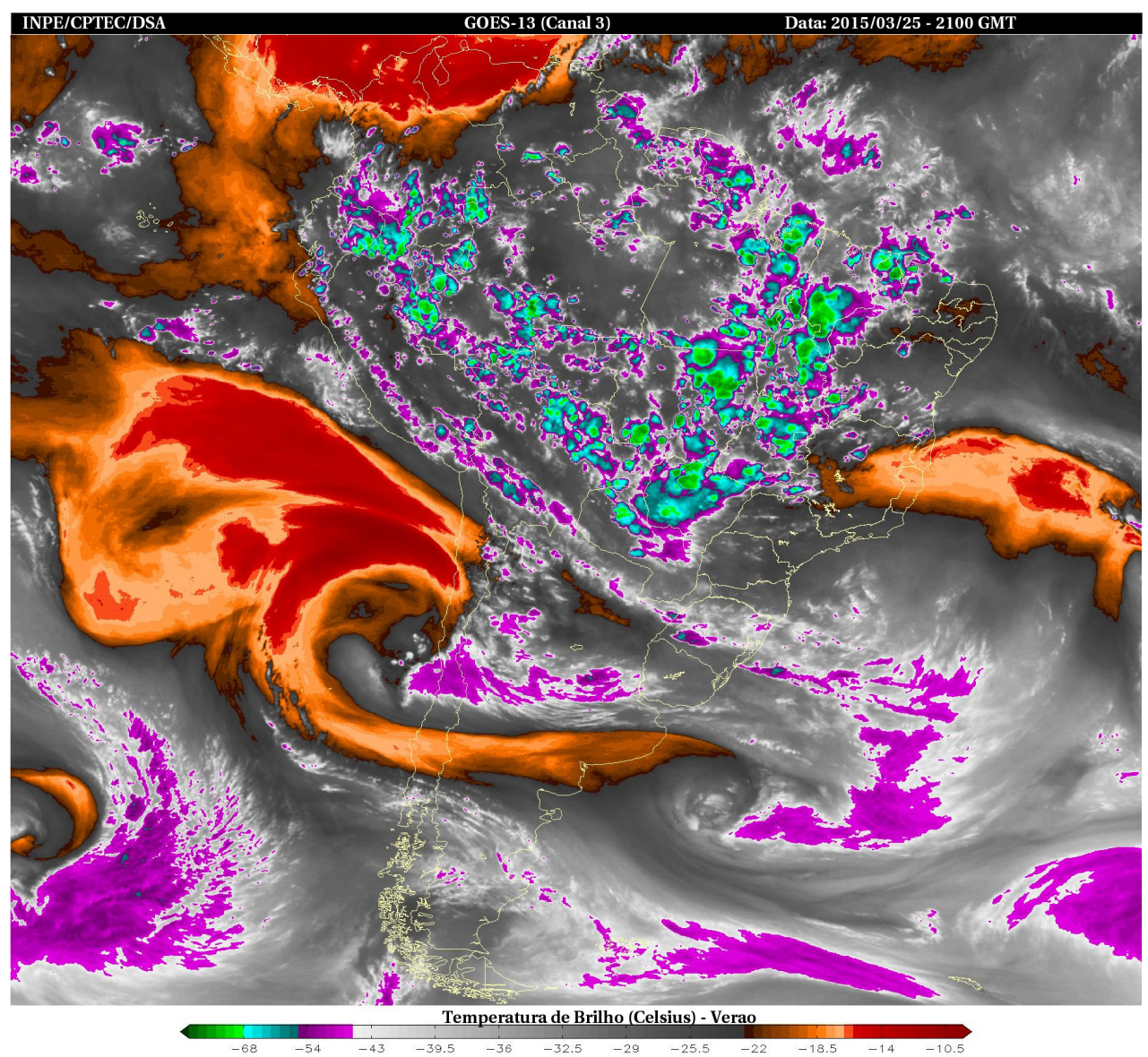

Image GOES water Vapor, March 25, 2015. Cut off Low that Caused the Disaster IN the region of Atacama. The colors indicate temperature of the cloud top. Source: Centro de Previsão de Tempo e Estudos Climáticos (CPTEC) 